J. Lake Sci. (湖泊科学), 2019, 31(2):336-344

DOI 10. 18307/2019. 0203

(c) 2019 by Journal of Lake Sciences

\title{
太湖蓝藻水华的扩张与驱动因素
}

张民, 阳 振, 史小丽**

(中国科学院南京地理与湖泊研究所湖泊与环境国家重点实验室, 南京 210008)

\begin{abstract}
摘 要: 蓝藻水华表征指标及驱动因子的多样性增加了研究人员、湖泊管理部门对于蓝藻水华扩张驱动因素的困惑, 本 研究通过整合太湖蓝藻水华长尺度研究的成果, 将蓝藻水华扩张区分为时间扩张、空间扩张和生物量扩张 3 个方面, 分析 各自的驱动因子, 系统阐述了当下太湖蓝藻水华的扩张和驱动因素. 太湖蓝藻水华的时间扩张呈现由夏季集中发生向春 季和秋冬季节扩张的趋势, 导致春季蓝藻水华发生的提前, 以及年度峰值的推迟; 空间扩张呈现由西北太湖向湖心和东 部湖区、乃至全湖扩张的趋势; 太湖蓝藻生物量自 2003 年以后一直呈现缓慢增加的趋势. 蓝藻水华时间扩张的驱动因素 相对独立, 主要受气象因子的影响, 风速和日照时间是主要驱动因子, 风速降低和日照时间延长均有助于蓝藻水华时间 的扩张; 空间扩张和生物量扩张则受气象因子和富营养化的双重影响,其中影响水华空间扩张的因子较多,富营养化和 气象因素的主次难以确定, 一般偶发性大面积蓝藻水华受气象因子驱动, 而频发性大面积蓝藻水华主要受营养盐空间分 布影响; 影响蓝藻生物量扩张的主要驱动因素为总磷, 另外氮磷比、水下可利用光和风速的变化也在一定程度上驱动了 太湖蓝藻生物量的扩张. 目前表征蓝藻水华强度通常利用空间扩张或生物量扩张指标, 但是均具有一定局限性, 相互间 也缺乏可比性, 各指标用于长尺度趋势研究更为可靠, 短尺度比较受方法缺陷影响较大, 应进一步开发表征水华蓝藻总 存量的指标以统一空间扩张和生物量扩张.
\end{abstract}

关键词: 太湖;蓝藻水华;营养盐;气候因素

\section{Expansion and drivers of cyanobacterial blooms in Lake Taihu}

\section{ZHANG Min, YANG Zhen \& SHI Xiaoli}

( State Key Laboratory of Lake Science and Environment, Nanjing Institute of Geography and Limnology, Chinese Academy of Sciences, Nanjing 210008, P.R.China)

\begin{abstract}
The diversity in proxies and drivers of cyanobacterial blooms expansion increased the confusion of understanding for cyanobacterial blooms expansion to scientists and lake managers. This study integrated the previous studies about long-term variation of cyanobacterial blooms in Lake Taihu, and divided the expansion into three aspects : temporal expansion, spatial expansion and biomass expansion, and discussed their trend and drivers. In time, the occurrence of cyanobacterial blooms shows the trend towards spring and autumn/winter from summer. The onset time of cyanobacterial blooms advances, and the annual peak delays. In space, cyanobacterial blooms expands towards center and east of the lake from the north and west. The cyanobacterial biomass increases gradually since 2003. Wind speed and sunshine hours are the primary factors influencing the temporal expansion. Decreasing wind speed and increasing sunshine hours favor the temporal expansion. The drivers for the spatial expansion are relative complicated, and difficult to disentangle the primary factors from nutrient and climate variables. Generally, the occasional large-area cyanobacterial blooms are driven by wind speed and wind direction, and the frequent large-area blooms are driven by nutrient. Total phosphorus is the primary factor driving the variation of cyanobacterial biomass, following by the ratio of total nitrogen to total phosphorus, underwater available light and wind speed. At present, the cyanobacterial blooms area and biomass usually are used to indicate the blooms intensity, both of which are inaccurate due to the defect of methods. Their proxies are reliable for long-term study, but seriously affected by defect of methods when they are used in short-term study. Therefore, it is necessary to build a new proxy as a substitution for bloom area and biomass to show the total cyanobacterial biomass in the whole lake. In addition, reducing phosphorus
\end{abstract}

* 国家自然科学基金项目 (31870447,31570457,31470520) 和江苏省水利厅科技项目(2017002ZB) 联合资助. 201807-27 收稿; 2018-08-15 收修改稿. 张民 (1978 ), 男, 博士, 副研究员; E-mail : mzhang@ niglas.ac.cn.

** 通信作者;E-mail:xlshi@ niglas.ac.cn. 
loading and decreasing phosphorus concentration are the main task of controlling cyanobacterial blooms in Lake Taihu.

Keywords: Lake Taihu; cyanobacterial blooms; nutrients ; climate variables

太湖是我国第三大淡水湖泊,水面面积 $2338.1 \mathrm{~km}^{2}$, 属于半封闭型浅水水泊, 平均水深 $1.89 \mathrm{~m}^{[1]}$. 湖水依赖 地表径流和湖面降水补给, 共有 160 余条人湖河流, 出水口集中于太湖的东部和北部, 分别由沙墩港、胥口港、 瓜涇港、南厍港等排人长江, 合计港渎 59 条. 其中东太湖出水量约占总出水量的 $67 \%$, 西太湖仅占 $33 \%{ }^{[2]}$. 但 是近年来一系列的水利工程已经显著改变了太湖原有的流场状况,如 2002 年开始实施的“引江济太”工程、近 年来实施的苔溪水系截水工程、东太湖引水工程等等. 现阶段太湖全湖处于轻度富营养化状态, 富营养区域呈 现由北部、西部向湖心和东部湖区扩张的趋势,蓝藻水华是太湖目前最严重的水环境问题 ${ }^{[3]}$.

太湖蓝藻水华的历史较久, 1950- 1960s 在太湖五里湖就可见蓝藻水华 ${ }^{[4]}, 1970-1980 \mathrm{~s}$, 开始在西北湖 区的局部水域偶发蓝藻水华,到 $1980 \mathrm{~s}$ 末期开始全年可见蓝藻水华,但是主要集中于夏季发生 ${ }^{[5]}$, 进人 21 世 纪, 蓝澡覆盖面积进一步扩大, 持续时间延长, 水华蓝藻生物量也明显增加 ${ }^{[6]}$. 富营养化的加剧通常被认为 是蓝藻水华扩张的主要原因 ${ }^{[7-8]}$, 近年来气候变化被提出是加剧蓝藻水华扩张的另一个重要因素 ${ }^{[9]}$. 尽管一 些研究已经开始关注富营养化、气候变化及其相互作用对蓝藻水华扩张的贡献 ${ }^{[10-11]}$, 但是针对具体湖泊,如 太湖, 这些通识性的研究无法做出针对性的解释, 更多的变量引人, 更增加了研究人员、湖泊管理部门对于 太湖蓝藻水华扩张驱动因素的困惑. 同时, 基于多指标表征, 多时间尺度分析的各类蓝藻水华研究结果的不 一致性也进一步增加了这种困惑.

因此, 本文将整合太湖蓝藻水华长尺度研究的成果, 分析太湖蓝藻水华扩张的时空变化模式, 并将蓝藻 水华扩张区分为时间扩张、空间扩张和总生物量扩张三个方面分析其主要的驱动因素, 阐明当下太湖蓝藻 水华扩张的驱动因子, 以期为太湖蓝藻水华防控策略的制定提供科学支撑.

\section{1 太湖蓝藻水华的表征因子}

近年来关于太湖蓝藻水华扩张的研究和报道日益增多, 关于蓝藻水华扩张特征描述的代用指标也多种 多样 ${ }^{[12-14]}$, 多样性的代用指标导致关于蓝藻水华扩张程度和驱动因素的不一致性. 综合各类代用指标, 可以 将其分为三大类,即蓝藻水华时间扩张指标、空间扩张指标和生物量扩张指标.

\section{1 蓝藻水华时间扩张表征}

蓝藻水华时间扩张主要指蓝藻水华在年内尺度上时间分布的扩张, 而表征这一过程的主要指标有蓝藻 水华年内持续时间 (annual duration)、年内首次发生时间 (onset time) ${ }^{[12,15]}$ 以及水华蓝藻生长季起始时间 (onset time of growing season) ${ }^{[13]}$ 等. 其中年内持续时间主要指通过卫星遥感影像以及人工巡测所发现的蓝 藻水华发生的月数, 受天气因素 (对遥感影像获取的影响) 和巡测频度的影响, 这一指标目前的精度仅限于 月尺度上, 尚未发现可用的更高精度的数据. 虽然通过 MODIS 等可以每天提供遥感影像的数据源可以获得 更多的数据, 但是在天气因素的影响下, 这种数据的不确定性显著上升. 首次发生时间是指通过遥感影像和 人工巡测首次发现蓝藻水华发生的时间, 通常以儒略日 (Julian Day) 表示. 这一指标同样受天气因素和巡测 频度的影响, 同时由于其是对发生日期的明确界定, 导致它的不确定性高于年内持续时间指标, 因此, 该指 标主要用于长时间序列分析, 其具有统计学意义, 但是仅比较个别年份的首次发生时间, 可能会引人较大的 误差. 水华蓝藻生长季起始时间主要是指超过水华蓝藻复苏生长温度的日期, 如微囊藻在超过 $9^{\circ} \mathrm{C}$ 时开始复 苏生长 ${ }^{[16]}$, 那么就可以将 5 天滑动平均的 $9^{\circ} \mathrm{C}^{[13]}$ 或者连续 10 天超过 $9^{\circ} \mathrm{C}^{[12]}$ 的日期作为水华蓝藻生长季起 始时间. 这个指标是一个间接反映蓝藻时间扩张的指标, 主要是因为这个指标更多反映的是温度变化, 微囊 藻复苏后, 还需要经历生长到水华形成的过程, 这个过程受营养盐和光照等条件的影响, 因此其无法直接反 映蓝藻水华的扩张过程.

\section{2 蓝藻水华空间扩张表征}

蓝藻水华空间扩张主要指蓝藻水华在年际尺度上空间分布的扩张, 表征这一过程的主要指标是蓝藻水 华的面积 ${ }^{[6,17]}$ 和水华蓝藻生物量的空间分布. 蓝藻水华面积的获取主要基于卫星遥感影像的解译, 近年来 随着遥感影像数据来源的丰富, 可以实现每日多幅影像的获取, 极大的提升了遥感影像数据的时间精度, 但 
是遥感影像的解译算法较多 ${ }^{[15,17-19]}$, 而解译方法的差异会造成蓝藻水华面积的明显差异. 水华蓝藻空间扩 张的生物量指标是水华蓝藻生长的真实反映, 通常采用采样监测后插值计算的方法获取, 但是用其反映空 间扩张却明显受制于采样点位的数量、空间分布以及采样频度,因此多用于短期研究.

\section{3 蓝藻水华生物量扩张表征}

蓝藻水华生物量的扩张主要指表征水华蓝藻总量指标的扩张, 而这些指标主要包括叶绿素 a 浓度、浮 游植物总生物量、优势蓝藻生物量 (微囊藻生物量) 等 ${ }^{[14,20-21]}$. 生物量的指标主要通过细胞计数、细胞体积的 测量等鉴定计数方法最终计算得出, 通常被认为是可靠的反映浮游植物生物量变化的指标. 叶绿素 a 浓度 和生物量两个指标具有显著的正相关性, 因此在诸多研究中也利用叶绿素 a 浓度替代生物量来反映浮游植 物生物量 ${ }^{[22-23]}$, 但是我们利用太湖 1993-2015 年的逐月数据研究发现, 随着蓝藻在总生物量中比例的增 加,利用叶绿素 a 浓度来表征生物量往往造成生物量的低估(图 1).
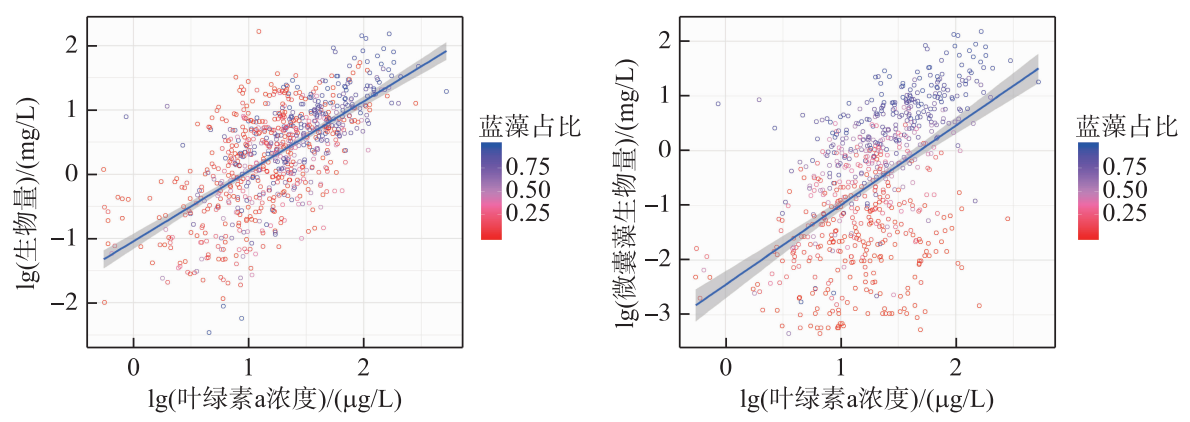

图 1 太湖浮游植物生物量与叶绿素 $\mathrm{a}$ 浓度的关系

(点的颜色差异表征蓝藻占比的不同,数据源于太湖湖泊生态系统研究站)

Fig.1 The relationship between biomass and chlorophyll-a concentration in phytoplankton of Lake Taihu ( Color bar indicates the ratio of cyanobacterial biomass to total biomass;

The data is from Taihu Laboratory for Lake Ecosystem Research, TLLER)

\section{2 太湖蓝藻水华的扩张趋势}

\section{1 太湖蓝藻水华的时间扩张趋势}

在全球变化的背景下,太湖区域气温呈现显著的增加趋势 ${ }^{[12]}$, 温度的增加使得水华蓝藻生长季节初始 时间提前, 并进一步促进了春季蓝藻水华更早的形成和更频繁的发生 ${ }^{[13]}$. 而蓝藻水华的初始发生时间, 在 过去的 20 几年间呈现不同的趋势, 1987-1997 年间,蓝藻水华初始发生时间逐年延后, 平均每年延后 5 天, 而 1997-2009 年间, 蓝藻水华初始发生时间逐年提前, 平均每年提前约 10 天 $^{[12,15]}, 2009$ 年以后蓝藻水华首 次发生时间基本维持在 4 月初. 同时也发现, 自 2005 年以后, 水华蓝藻从进人生长期到蓝藻水华首次发生 所需的时间明显短于 2005 年以前, 特别是在 2006 年, 从复苏到首次发生仅隔 9 天. 蓝藻水华的持续时间则 表现为显著增加, 1998 年以前太湖蓝藻水华主要集中发生在 6-8 月的某个月份, 而 1998 年以后蓝藻水华 发生的月份开始增加 ${ }^{[12,15]}$, 到 2005 年以后, 每年有 8 10 个月可以发现由蓝藻水华的发生. 2009-2011 年 间, 蓝藻水华全年皆可见, 即使在冬季依然能通过卫星遥感影像发现有少量的蓝澡水华出现 ${ }^{[24]}$, 虽然这些冬 季表面水华蓝藻活性较低,多为秋季残余待降解的蓝藻, 间接表明太湖地区水华蓝藻降解过程的缓慢.

\section{2 太湖蓝藻水华的空间扩张趋势}

1950s 太湖的蓝藻水华仅见于五里湖, 1960s 中期, 㕻头渚附近水域开始出现蓝藻水华, 1970s 中期在焦 山附近有大片水华, $1980 \mathrm{~s}$ 初期, 五里湖和梅梁湾约有 $2 / 5$ 湖区每年夏季出现水华, 至 $1980 \mathrm{~s}$ 末期, 梅梁湾的 3/5 水域可见蓝藻水华发生, 同时西部湖区亦可见蓝藻水华, $1990 \mathrm{~s}$ 中期, 蓝藻水华几乎覆盖整个梅梁湾, 同 时竺山湾、西部湖区和北部湖心区亦有蓝藻水华发生 ${ }^{[25]}, 2000$ 年初, 太湖的西北湖区,包括梅梁湾、竺山湾、 贡湖湾和西部湖区均有蓝藻频繁发生, 可见蓝藻水华区域占太湖面积的 $2 / 5,2010$ 年以后太湖蓝藻水华进一 
步向湖心和东部湖区扩张,2017 年太湖蓝藻水华最大面积已经占全湖面积的一半左右. 在空间分布上,太湖 蓝藻水华的扩张经历了一个从北部湖区的梅梁湾和竺山湾逐渐扩展到西部湖区和湖心区, 并逐步向东部湖 区蔓延的过程.

上述关于太湖蓝藻水华空间扩张的描述多是基于定性观测的结果,而关于太湖蓝藻水华面积扩张的定 量研究 ${ }^{[6,15,18]}$ 主要得益于卫星遥感方法的应用, 根据卫星遥感影像资料, 太湖蓝藻水华大面积暴发始于 1987 年 6 月,覆盖面积约为 $62 \mathrm{~km}^{2}$,之后一直到 2000 年,水华覆盖面积都基本维持在这一水平, 2004 年以后,蓝 藻水华面积迅速扩张, 2004 年最大面积为 $197 \mathrm{~km}^{2}, 2005$ 年为 $317 \mathrm{~km}^{2}, 2006$ 年为 $806 \mathrm{~km}^{2}, 2007$ 年 979 $\mathrm{km}^{2[6,17]} .2007$ 年以后太湖蓝藻水华面积有所下降, 但相比 2006 年以前仍处于较高水平, 中间个别年份仍会 有大面积水华发生,如,2013 年最大水华面积约 $989 \mathrm{~km}^{2}, 2016$ 年为 $702 \mathrm{~km}^{2}, 2017$ 年 $1150 \mathrm{~km}^{2} .2003-2013$ 年太湖年平均水华面积从 $115.91 \mathrm{~km}^{2}$ 增加到 $167.77 \mathrm{~km}^{2[19]}$.

\section{3 太湖蓝藻水华的生物量扩张趋势}

太湖蓝藻水华生物量的扩张趋势需要汇集太湖长时间尺度和覆盖全湖监测点位的数据, 目前仍未见有 覆盖如此时空尺度的监测结果见于发表, 众多的关于太湖生物量变化趋势的研究通常只集中于特定湖区或 典型湖区 ${ }^{[20-21,26-27]}$. 尽管如此, 根据这些经典的研究文献, 我们依然能够得出太湖水华蓝藻生物量变化的趋 势. 总体来讲, 太湖水华蓝藻生物量呈现缓慢增加的趋势, 湖心和东部湖心水华蓝藻生物量扩张的趋势明显 高于西北部湖区,而在时间上,秋、冬季水华蓝藻生物量的增加更为显著(图 2).

在空间上, 梅梁湾 1997 年以前, 叶绿素 a 浓度呈现明显的升高趋势, 1997-2002 年叶绿素 a 浓度呈现 下降趋势, 2003-2008 年保持相对稳定,2009 年显著增高, 2009-2012 年逐步下降, 2012-2017 年呈现明显 增高的趋势 (图 3). 而湖心区域自 1998 年以后保持逐步抬升趋势 ${ }^{[28]}$, 东部湖区自 2016 年水草大面积减少 以后,水华蓝藻生物量也呈现明显的增加趋势.

在时间上, 生物量的增加主要体现在秋、冬季的增加, 在 2007 年以前, 太湖生物量的峰值通常出现在 7 月, 而 2008 年以后, 7 月的生物量保持了原来峰值的水平, 随后继续增加, 峰值出现在 8-9 月, 之后的 1012 月生物量也明显高于历史同期水平.

利用水华面积和生物量表征的蓝藻水华扩张在一定程度具有一致性, 但是其所表征的扩张程度不同年 份间存在明显的差异,通过梅梁湾及湖心区域的蓝藻水华面积与叶绿素 a 浓度的对比分析可以发现, 2007 年和 2011 年的大面积水华, 所对应的蓝藻生物量远没有达到面积扩张的程度, 而 2003 年和 2009 年生物量 很高, 但是蓝藻水华的面积却并没有达到生物量的扩张程度 (图 4). 这种差别主要源于两个表征指标各自 的缺陷,首先对于水华面积,虽然水华面积能够反映更多的空间分布,但是对于不同区域水华厚度却无法获 取, 因此, 更大的面积并不能代表更高的生物量; 其次对于生物量, 这个指标主要基于采样监测获取数据, 采 样监测受采样点位的限制, 如果采样区域有水华发生, 那么藻类的生物量就会很高, 如果采样区域无水华发 生, 藻类生物量就会相对较少. 因此, 这两个方法获得的蓝藻水华扩张在长时间尺度上能够反映水华扩张的 趋势, 但是在短尺度上, 如比较两年间水华的差异则可能存在较大的问题,整合遥感反演和野外监测结果构 建水华蓝藻总存量模型,计算不同时间蓝藻总存量作为蓝藻水华扩张的指标应该是以后的发展方向.

\section{3 太湖蓝藻水华扩张的驱动因素}

\section{1 太湖蓝藻水华的时间扩张驱动因素}

太湖过去 20 多年蓝藻水华的起始时间变化与温度、风速、日照时间和太阳辐射强度等气候变化因子的 变化强度具有显著的相关性, 与营养盐以及降雨等变量的变化关系不显著, 蓝藻水华的持续时间与温度等 气候变化因子以及营养盐的关系不显著. 通过多元线性回归分析可以发现, 在太湖高营养盐浓度的背景下, 近 20 年来蓝藻水华强度的扩张主要受气候变化因子的影响, 而风速和日照时间是解释蓝藻水华扩张的主 要因子, 这两个因子解释了 $84.6 \%$ 的蓝藻水华初始发生时间提前, $58.9 \%$ 的蓝藻水华年内持续时间延长的变 化 ${ }^{[12]}$. 更低的风速和更长的日照时间均能显著促进蓝藻水华的时间扩张, 在大型浅水湖泊中, 风是诱导水 体混合的重要驱动因子, 风速的降低将增加水体的稳定性, 这将有利于水华蓝藻的上浮, 形成表面水华. 过 去 60 年 (1956-2015 年) 太湖的风速显著下降, 近年来 $3 \mathrm{~m} / \mathrm{s}$ 以下的风速占比增加显著(图 5), 而低于这一 

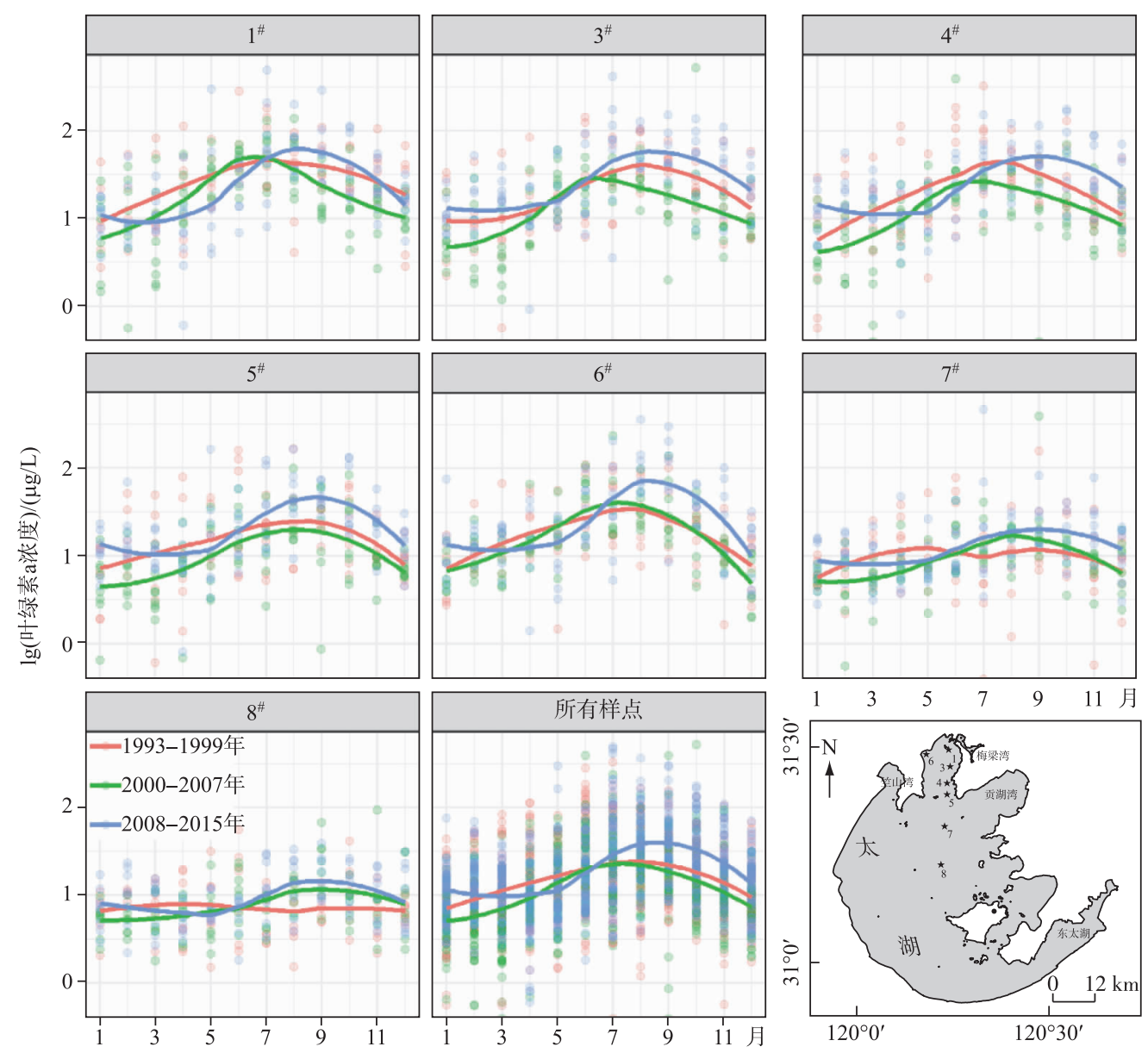

图 2 太湖梅梁湾及湖心不同时间段叶绿素 a 浓度的逐月变化

(右下角为点位分布图,数据源于太湖湖泊生态系统研究站)

Fig.2 The monthly variation of chlorophyll-a in different sites locating in Meiliang Bay and lake center of Lake Taihu ( The map in lower right corner shows the location of the sites, the data is from TLLER)

阈值, 水华蓝藻将主要集中于表层水体, 形成遥感可探测的蓝藻水华 ${ }^{[29]}$. 同时, 上浮到表层水体的蓝藻更易 于获取光能满足自身生长, 特别是在春秋季节, 表层水体温度和光照强度均低于水华蓝藻的生长限值时, 更 长的日照时间将有利于水华蓝藻在表层水体中的生长.

上述的研究中我们发现,营养盐的变化对太湖蓝藻水华时间扩张的贡献不显著,这主要归处于太湖较 高的营养盐水平. 目前太湖的营养盐水平虽然对蓝藻的生长及蓝藻水华的强度仍有限制作用 ${ }^{[30]}$, 但是其足 以维持蓝藻水华的持续发生, 而蓝藻水华时间扩张的指标更多体现的是蓝藻水华物候学的变化, 与蓝藻水 华的强度关系不大, 因此, 当营养盐水平超过蓝藻水华发生的阈值之后, 营养盐将不再成为限制蓝藻水华时 间扩张的因素. 已有的综述研究, 基于蓝藻的生理特性分析, 认为全球变化导致的温度升高有利于蓝藻的生 长, 促进春季蓝藻水华更早的发生以及持续时间的延长 ${ }^{[9]}$, 但是野外观测往往不能充分支持温度升高促进 蓝藻水华发生的观点 ${ }^{[11]}$, 我们的研究也没有发现, 在气候变化影响研究中广受关注的温度在驱动太湖蓝藻 水华时间扩张中起主要的驱动作用. 平均温度的升高不能有效解释蓝藻水华强度扩张主要缘于温度升高效 应的复杂性, 野外研究中经常把温度升高看成一个整体事件, 没有把温度的直接影响从温度诱导的如水体 稳定性增加、风速降低等间接影响中剥离出来, 而这些因素都直接或间接地影响藻类的生长与水华的形成. 


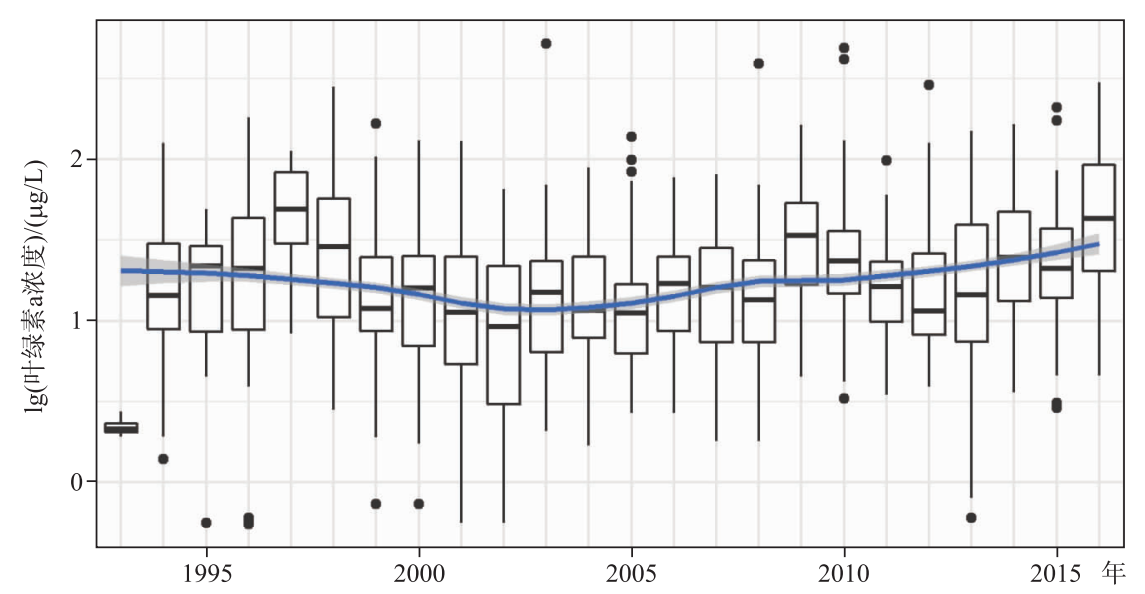

图 3 1993-2016 年太湖梅梁湾及湖心区域叶绿素 a 浓度变化趋势(数据源于太湖湖泊生态系统研究站)

Fig.3 The trend of annual averaged chlorophyll-a concentration from 1993 to 2016 in

Meiliang Bay and lake center of Lake Taihu (The data is from TLLER)

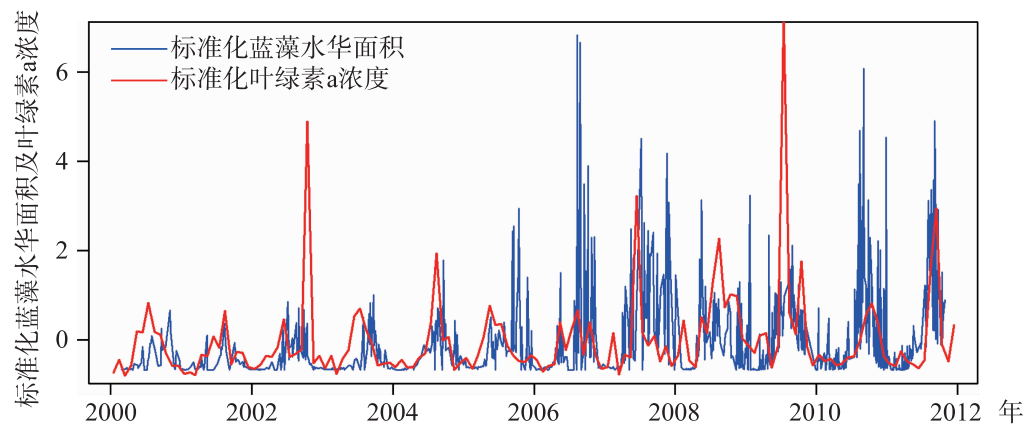

图 4 太湖梅梁湾及湖心区域标准化蓝藻水华面积与叶绿素 a 浓度的差异 (数据源于太湖湖泊生态系统研究站)

Fig.4 The difference between standardized cyanobacterial blooms area and chlorophyll-a concentrations in Meiliang Bay and lake center of Lake Taihu (The data is from TLLER)

\section{2 太湖蓝藻水华的空间扩张驱动因素}

太湖蓝藻水华的空间扩张主要受营养盐的空间分布变化以及气象因子的变化影响,其中最主要的影响 因子有总磷浓度、平均温度、日照时间 ${ }^{[31]}$ 、风速和风向、气压 ${ }^{[17,19,32]}$ 等. 影响蓝藻水华面积的因素众多, 难以 明确其主导的驱动因素, 这与蓝藻水华面积形成过程的复杂性相关. 蓝藻水华面积的形成,首先要有一定量 的蓝藻生物量作为支撑, 蓝藻生物量的累积过程主要受营养盐浓度、温度和光照的影响; 生物量累积后的空 间分布也是决定水华面积大小的重要因素,而这一过程主要受风速、风向的影响, 风速的大小决定了水华蓝 藻的垂向分布, 而风速和风向共同决定了水华蓝藻的空间分布 ${ }^{[26]}$, 小于 $3 \mathrm{~m} / \mathrm{s}$ 的东南风将有助于太湖水华 蓝藻的空间扩张; 最近也有研究表明气压也是驱动蓝藻水华面积扩张的因子 ${ }^{[19]}$, 但目前尚无法将该因子同 蓝藻的生理、生态过程建立有效的联系,其内在机制仍有待深人探讨.

太湖蓝藻水华空间扩张的趋势呈现由西北太湖向湖心、东部湖区、乃至全湖扩张的趋势 ${ }^{[21]}$, 这一扩张的 趋势与近年来太湖营养盐的空间变化趋势相一致,2016 年以来太湖东部湖区水草分布面积急剧缩小,虽然 目前尚无定量的水草面积萎缩与东部及湖心偏东区域水体总磷浓度升高之间的关系, 但是根据以往的研究 依然可以明确缺少水草对内源磷的固定作用, 内源磷的释放必将增加, 同时缺少了水草的竞争抑制作用,增 


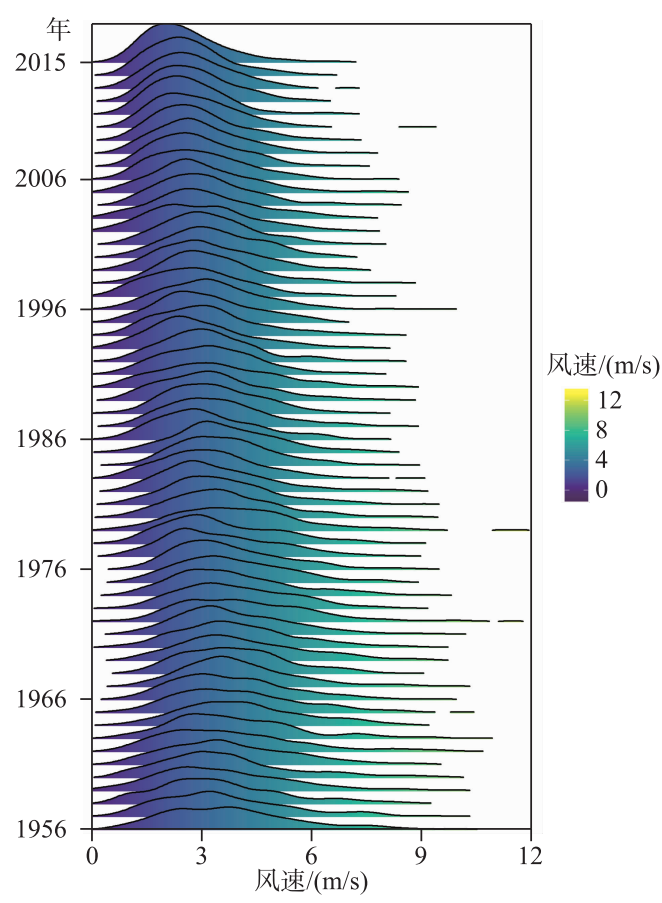

图 5 1956-2015 年太湖风速的频度分布 (数据来源于国家气象台站西山站\#58358)

Fig.5 The frequency distribution of wind speed in Lake Taihu from 1956 to 2015 ( The data are from Xishan Station \#58358 of the China Meteorological Administration)
加的营养盐必将促进藻类的大量生长, 增加了这些区 域发生蓝藻水华的风险. Zhang 等 ${ }^{[31]}$ 通过对春季太湖 蓝藻水华面积的分析发现, 总磷和温度的交互作用以 及日照时间是影响太湖春季蓝藻水华面积变化的主要 因子,这两个因子可以解释面积变化的 $69 \%$. Shi 等 ${ }^{[19]}$ 通过对全年平均水华面积的分析发现, 太湖蓝藻水华 的面积与气压和风速呈反比, 即随着气压和风速的降 低, 蓝藻水华的面积明显增加, 但是个别年份出现异 常, 如 2006 和 2007 年. 综合前人研究, 偶发性、持续时 间较短的大面积蓝藻水华, 可能主要受风速风向的影 响, 即一定生物量水华蓝藻在气象条件下的空间再分 配, 而年内多次、持续时间相对较长的大面积蓝藻水 华,其可能主要受营养盐空间分布变化的影响.

\section{3 太湖蓝藻水华的生物量扩张驱动因素}

太湖水华蓝藻生物量变化的驱动因子主要包括营 养盐、温度、可利用光强度、风速等. Chen 等 ${ }^{[26]}$ 通过多 年的监测数据分析发现, 太湖的水华蓝藻生物量与总 磷和温度的变化显著正相关. Liu 等 $^{[14]}$ 通过更为细致 的分析发现, 微囊藻的生物量与氮磷比 (总氮: 总磷) 呈负相关, 与氨氮与硝态氮的比例、水温和 $\mathrm{pH}$ 正相关, 当氮磷比低于 30 , 氨氮与硝态氮比例低于 1 时, 微囊藻 生物量占总生物量的比例明显升高, 而微囊藻适宜的 温度为 $25 \sim 30^{\circ} \mathrm{C}$. 水华期间的 $\mathrm{pH}$ 通常高于 8 . Shi 等 ${ }^{[19]}$ 通过遥感解译的叶绿素浓度分析了其影响因素, 发现温度和营养盐是影响叶绿素变化的主要因子. 通 过对太湖梅梁湾及湖心多年蓝藻生物量变化的分析发

现, 营养盐 (包括总氮、总磷和氮磷比)、光热过程 (温度和可利用光强度) 和水体稳定性 (风速) 3 类指标能够 解释蓝藻生物量变化的 $57.9 \%$, 其中营养盐 (总磷和氮磷比) 单独能够解释蓝藻生物量变化的 $29 \%$, 温度对 蓝藻变化的影响不显著, 但是水下可利用光可以单独解释蓝藻生物量变化的 $10.2 \%$, 风速的解释量为 $8.4 \%$, 进一步通过微囊藻生物量的分析与这一结果相一致 ${ }^{[33]}$.

我们的分析结果与前期研究最大的差异是温度对蓝藻生物量变化的贡献, 这主要归处于分析尺度的差 异,我们的分析是基于年际尺度的变化开展的分析, 尽管受气候变暖的影响, 太湖地区升温显著,但是升温 的幅度有限, 在有限的升温环境下, 更大尺度的营养盐、光照、风速等环境因子的变化对蓝藻生物量的影响 将更为显著, 有限变化的温度对蓝藻生物量变化的影响极有可能被不同类群藻类间的补偿效应所抵消,而 无法观察到显著的影响 ${ }^{[34]}$. 前期的研究所用的蓝藻生物量和温度数据多为月度或更高精度的日均值数据 (遥感反演数据), 这些数据中温度具有明显的季节性差异, 因此前期研究结果中温度对水华蓝藻生物量的 影响主要反映的是年内尺度,季节性温度变化对年内蓝藻水华变化的影响.

综合太湖蓝藻水华时间、空间和生物量扩张的驱动因素可以发现, 蓝藻水华的时间扩张相对独立, 主要 受气象因子的影响, 空间扩张和生物量的扩张则受气象因子和富营养化的双重影响, 其中生物量的扩张受 营养盐的影响更多, 这与蓝藻水华的形成过程密切相关. 另外, 上述的众多研究尽管定量了蓝藻水华扩张的 驱动因素, 但是仍发现有少部分变化无法给出解释, 这可能与太湖的人为调节有关, 如蓝藻打捞、“引江济 太”、增殖放流等.

\section{4 结论}

1) 太湖蓝藻水华的扩张主要可分为时间扩张、空间扩张和生物量扩张三个方面,每种扩张的表征指标 
不同, 其所反映的趋势和驱动因子也各不相同 (表 1), 相互间缺乏可比性, 因此在进行蓝藻水华扩张的研究 过程中应明确对应指标,避免造成混乱.

\section{表 1 太湖蓝藻水华扩张的表征指标和驱动因子}

Tab.1 The proxies and divers for cyanobacterial blooms expansion in Lake Taihu

\begin{tabular}{llll}
\hline & 表征指标 & 数据来源 & 驱动因子 \\
\hline 时间扩张 & 生长季节起始时间 & 气象数据 & 温度 \\
& 初次发生时间 & 遥感解译 & 风速、日照时间 \\
& 持续时间 & 遥感解译 & 风速、日照时间 \\
空间扩张 & 水华面积 & 遥感解译 & 营养盐、温度、风速、风向、日照时间、气压 \\
& 生物量数据(插值) & 采样监测 & \\
生物量扩张 & 叶绿素 & 采样监测 & 总磷、氮磷比、可利用光、风速 \\
& 生物量 & 采样监测 & 总磷、氮磷比、可利用光、风速 \\
\hline
\end{tabular}

2) 太湖蓝藻水华的时间扩张呈现由 7-8 月集中发生向春季和秋、冬季节扩张的趋势,导致春季蓝藻水 华发生的提前, 以及年度峰值的推迟 (由 7-8 月推迟至 8-9 月); 空间扩张呈现由西北太湖向湖心和东部 湖区、乃至全湖扩张的趋势; 生物量扩张虽然在不同点位、不同年份间略有波动, 但是自 2003 年以后一直呈 现缓慢增加的趋势.

3) 风速降低和日照时间增加促进太湖蓝藻水华的时间扩张;空间扩张方面,偶发性大面积蓝藻水华受 风速风向驱动, 而频发性大面积蓝藻水华主要受营养盐空间分布影响; 总磷仍是太湖水华蓝藻生物量扩张 的主要驱动因素, 另外氮磷比、水下可利用光和风速的变化也在一定程度上驱动太湖蓝藻生物量的扩张. 致谢: 太湖湖泊生态系统研究站及中国国家气象台站提供太湖部分相关数据和气象数据,在此表示感谢.

\section{5 参考文献}

[ 1 ] Wang SM, Dou HS eds. China lakes. Beijing: Science Press, 1998. [王苏民, 窦鸿身. 中国湖泊志. 北京: 科学出版 社, 1998.]

[ 2 ] Qin BQ, Hu WP, Chen WM et al. Process and echanism of water environment evolument in Lake Taihu. Beijing: Science Press, 2004. [秦伯强, 胡维平, 陈伟民等. 太湖水环境演化过程与机理. 北京: 科学出版社, 2004.]

[ 3 ] Bulletin on environmental conditions in China. 2016. [中国环境状况公报. 2016.]

[ 4 ] Xie P ed. Historical development of cyanobacteria with bloom disaster in Lake Taihu. Beijing: Science Press, 2008. [ 谢 平. 太湖蓝藻的历史发展与水华灾害. 北京: 科学出版社, 2008.]

[ 5 ] Nanjing Institute of Geography and Limnology, Water Resources Protection Bureau of the Taihu Catchment eds. Water environment, ecology and eutrophication in Lake Taihu (1994-1995). Nanjing: Nanjing Institute of Geography and Limnology, 1997. [中国科学院南京地理与湖泊研究所, 太湖流域水资源保护局. 太湖水环境生态及富营养化研究 (1994-1995). 南京: 中国科学院南京地理与湖泊研究所, 1997.]

[ 6 ] Ma RH, Kong FX, Duan HT et al. Spatio-temporal distribution of cyanobacteria blooms based on satellite imageries in Lake Taihu, China. J Lake Sci, 2008, 20(6) : 687-694. DOI:10.18307/2008.0605. [马荣华, 孔繁翔, 段洪涛等. 基 于卫星遥感的太湖蓝藻水华时空分布规律认识. 湖泊科学, 2008, 20(6) : 687-694.]

[ 7 ] Reynolds CS ed. The ecology of freshwater phytoplankton. Cambridge, UK: Cambridge University Press, 1984.

[ 8 ] Reynolds CS ed. Ecology of phytoplankton (Ecology, biodiversity and conservation). Cambridge, UK: Cambridge University Press, 2006.

[ 9 ] Paerl HW, Huisman J. Climate: Blooms like it hot. Science, 2008, 320: 57-58.

[10] Rigosi A, Carey CC, Ibelings BW et al. The interaction between climate warming and eutrophication to promote cyanobacteria is dependent on trophic state and varies among taxa. Limnology and Oceanography, 2014, 59: 99-114.

[11] Wagner C, Adrian R. Cyanobacteria dominance: Quantifying the effects of climate change. Limnology and Oceanography, 2009, 54: 2460-2468.

[12] Zhang M, Duan H, Shi X et al. Contributions of meteorology to the phenology of cyanobacterial blooms: implications for future climate change. Water Research, 2012, 46: 442-452. 
[13] Deng J, Qin B, Paerl HW et al. Earlier and warmer springs increase cyanobacterial (Microcystis spp.) blooms in subtropical Lake Taihu, China. Freshwater Biology, 2014, 59 (5) : 1076-1085.

[14] Liu X, Lu X, Chen Y. The effects of temperature and nutrient ratios on Microcystis blooms in Lake Taihu, China: An 11year investigation. Harmful Algae, 2011, 10 (3) : 337-343.

[15] Duan H, Ma R, Xu X et al. Two-decade reconstruction of algal blooms in China's Lake Taihu. Environmental Science \& Technology, 2009, 43 (10): 3522-3528.

[16] Cao H, Tao Y, Kong F et al. Relationship between temperature and cyanobacterial recruitment from sediments in laboratory and field studies. Journal of Freshwater Ecology, 2008, 23(3) : 405-412.

[17] Hu CM, Lee Z, Ma RH et al. Moderate resolution imaging spectroradiometer (MODIS) observations of cyanobacteria blooms in Taihu Lake, China. Journal of Geophysical Research, 2010, 115( C4) : C04002.

[18] Zhang Y, Ma R, Duan H et al. A novel algorithm to estimate algal bloom coverage to subpixel resolution in Lake Taihu. IEEE Journal of Selected Topics in Applied Earth Observations and Remote Sensing, 2014, 7(7) : 3060-3068.

[19] Shi K, Zhang Y, Zhou Y et al. Long-term MODIS observations of cyanobacterial dynamics in Lake Taihu: Responses to nutrient enrichment and meteorological factors. Scientific Reports, 2017, 7: 40326.

[20] Chen Y, Fan C, Teubner K et al. Changes of nutrients and phytoplankton chlorophyll-a in a large shallow lake, Taihu, China: An 8-year investigation. Hydrobiologia, 2003, 506 (1) : 273-279.

[21] Zhu GW, Qin BQ, Zhang YL et al. Variation and driving factors of nutrients and chlorophyll-a concentrations in northern region of Lake Taihu, China, 2005-2017. J Lake Sci, 2018, 30(2) : 279-295. DOI:10.18307/2018.0201. [朱广伟, 秦 伯强, 张运林等. 2005-2017 年北部太湖水体叶绿素 a 和营养盐变化及影响因素. 湖泊科学, 2018, 30(2): 279-295.]

[22] Vallina SM, Follows M, Dutkiewicz S et al. Global relationship between phytoplankton diversity and productivity in the ocean. Nature Communications, 2014, 5: 4229. DOI: 10.1038/ncomms5299(2014).

[23] Zhang M, Straile D, Chen F et al. Dynamics and drivers of phytoplankton richness and composition along productivity gradient. Science of the Total Environment, 2018, 625: 275-284.

[24] Ma J, Qin B, Paerl HW et al. The persistence of cyanobacterial (Microcystis spp.) blooms throughout winter in Lake Taihu, China. Limnology and Oceanography, 2016, 61(2) : 711-722.

[25] Sun SC, Huang YP eds. Lake Taihu. Beijing: Ocean Press, 1993. [孙顺才, 黄渏平. 太湖. 北京: 海洋出版 社, 1993.]

[26] Chen Y, Qin B, Teubner K et al. Long-term dynamics of phytoplankton assemblages: Microcystis-domination in Lake Taihu, a large shallow lake in China. Journal of Plankton Research, 2003, 25(4) : 445-453.

[27] Zhu W, Tan YQ, Wang RC et al. The trend of water quality variation and analysis in typical area of Lake Taihu, 20102017. J Lake Sci , 2018, 30(2) : 296-305. DOI: 10.18307/2018.0202. [朱伟, 谈永琴, 王若辰等. 太湖典型区20102017 年间水质变化趋势及异常分析. 湖泊科学, 2018, 30(2): 296-305.]

[28] Qin BQ, Wang XD, Tang XM et al. Drinking water crisis caused by eutrophication and cyanobacterial bloom in Lake Taihu, cause and measurement. Advance in Earth Science, 2007, 22(9): 896-906. [秦伯强, 王小冬, 汤祥明等. 太湖 富营养化与蓝藻水华引起的饮用水危机一一原因与对策. 地球科学进展, 2007, 22(9) : 896-906.]

[29] Cao HS, Kong FX, Luo LC et al. Effects of wind and wind-induced waves on vertical phytoplankton distribution and surface blooms of Microcystis aeruginosa in Lake Taihu. Journal of Freshwater Ecology, 2006, 21(2) : 231-238.

[30] Xu H, Paerl HW, Qin B et al. Nitrogen and phosphorus inputs control phytoplankton growth in eutrophic Lake Taihu, China. Limnology and Oceanography, 2010, 55(1): 420-432.

[31] Zhang M, Qin B, Yu Y et al. Effects of temperature fluctuation on the development of cyanobacterial dominance in spring: implication of future climate change. Hydrobiologia, 2016, 763: 135-146.

[32] Nanjing Institute of Geography and Limnology, Chinese Academy of Sciences. On the cause of cyanophyta bloom and pollution in water intake area and emergency measures in Meiliang Bay, Lake Taihu in 2007. J Lake Sci, 2007, 19(4) : 357358. DOI: $10.18307 / 2007.0401$. [中国科学院南京地理与湖泊研究所. 太湖梅梁湾 2007 年蓝藻水华形成及取水口 污水团成因分析与应急措施建议. 湖泊科学, 2007, 19(4): 357-358.]

[33] Zhang M, Shi X, Yang Z et al. Long-term dynamics and drivers of phytoplankton biomass in eutrophic Lake Taihu. Science of the Total Environment, 2018, 645: 876-886.

[34] Jochimsen MC, Kümmerlin R, Straile D. Compensatory dynamics and the stability of phytoplankton biomass during four decades of eutrophication and oligotrophication. Ecology Letters, 2012, 16: 81-89. 